\title{
O INÍCIO DA DOCÊNCIA DE UMA PROFESSORA CONSIDERADA BEM-SUCEDIDA: APONTAMEN- TOS A PARTIR DE RELATOS ORAIS
}

\section{THE BEGINNING OF TEACHING OF A SUC- CESSFUL TEACHER: NOTES FROM ORAL RE- PORTS}

\author{
André Luiz Sena MARIANO* \\ Juliane Aparecida Ribeiro DINIZ** \\ Regina Maria Simões Puccinelli TANCREDI***
}

Resumo: Objetivou-se, com esta pesquisa, conhecer a história de vida de uma professora, privilegiando-se os aspectos referentes ao seu início de carreira, e gerar novos conhecimentos sobre os saberes e fazeres docentes. A metodologia empregada foi a narrativa oral, utilizando-se de roteiro semi-estruturado elaborado pelos pesquisadores. Pelos dados coletados, percebeu-se que a professora não viveu o choque da realidade em seu início profissional e que a entrada dos professores na carreira depende de seus conhecimentos, de suas experiências de vida e do modelo 'funcional' que estão vivenciando.

Palavras-chave: Relatos Orais. Professor iniciante. Choque da realidade. Formação docente.

Abstract: The aim of this research was to know the his-
tory of life of a teacher highlighting the aspects of the
beginning of her career. Another aim was to generate
new knowledge about teachers' know how and teaching
tasks. The methodology adopted was the oral narrative
using a semi-structure guideline elaborated by the rese-
archers. From the data collected it could be noticed that

* Mestre em Educação - PPGE/UFSCar - e-mail: alsmariano@yahoo.com.br

** Mestre em Educação - PPGE/UFSCar - e-mail: julianerd@cultura.com.br

*** Doutora em Educação - PPGE/UFSCar - e-mail: drpt@power.ufscar.br 
the teacher did not experience the reality shock in the beginning of her career and that the entering of teachers into the career depends on their knowledge, on their life experiences and on the 'functional` model they are experiencing

Keywords: Oral reports. Beginning teacher. Reality chock. Teacher education.

\section{INTRODUÇÃO}

Os estudos, de caráter qualitativo, sobre histórias e relatos orais de vida dos professores, fazem parte de uma vertente de pesquisa que busca dar voz e vez aos professores, por meio de reflexões sobre a (auto) formação e a formação de novos educadores.

Assim, trabalhar com relatos e histórias de vida é trazer à tona discussões sobre temáticas, questões, indagações e dimensões da vida social e da história pessoal que extrapolam os cânones e preocupações convencionais da academia. Trata-se, ainda, de dar importância a aspectos que academicamente parecem não dispor dessa importância, como, por exemplo, o afeto. Por meio dos relatos orais, viabilizam-se conhecimentos que falam sobre as imagens, os saberes e os fazeres: conhecimentos que tratam das identidades assumidas e transformadas daqueles que vão se colocando na profissão docente.

\section{OPÇÕES METODOLÓGICAS}

O recurso metodológico da análise do relato oral de história de vida tem sido bastante utilizado na atualidade, a partir do estudo de narrações de vida de diversos professores e suas relações no ambiente sociocultural. Percebe-se que as experiências e "[...] o estilo de vida do professor dentro e fora da escola, as suas identidades e culturas ocultas têm impacto sobre os modelos de ensino e sobre a prática educativa" (GOODSON, 1992, p. 72).

Durante muito tempo, a formação dos docentes esteve baseada no modelo de racionalidade técnica, o qual visava formar o professor para aplicar técnicas, metodologias e teorias prontas - sem questionamentos ou reflexões, subestimando os saberes práticos - e 
ignorava a realidade única de cada ambiente escolar. Nesse modelo pouco se pesquisava a prática pedagógica e, tampouco, a história de vida dos professores, porque se considerava a carreira docente como desprovida de subjetividade.

Nas últimas décadas, tal modelo da racionalidade técnica tem sido amplamente questionado, embora não superado, e em seu lugar tem-se defendido o paradigma da racionalidade prática na formação dos professores, modelo em que os saberes práticos e a experiência profissional passam a ser considerados como conhecimentos importantes para a formação dos profissionais da educação.

O modelo da racionalidade prática percebe o processo de formação do professor como contínuo e o próprio docente como sujeito ativo de seu desenvolvimento profissional. Consideram-se, nessa formação, os "[...] saberes e as competências docentes como resultados não só da formação profissional e do exercício da docência, mas também de aprendizagens realizadas ao longo da vida, dentro e fora da escola" (MIZUKAMI et al., 2002, p.31). Assim, o desenvolvimento profissional do docente envolve valores, ideais, afetos, crenças, experiências, interesses e práticas sociais, profissionais e políticas.

Dessa forma, o recurso metodológico das histórias de vida e dos relatos orais dos professores é adotado como um caminho importante e significativo para compreensão e descrição do percurso e desenvolvimento profissional dos docentes, possibilitando, assim, a geração de novos conhecimentos sobre a formação de professores.

A escolha desse assunto para pesquisa deve-se à crença de que só é possível construir um conhecimento pedagógico científico e um ensino de qualidade na medida em que se tem "[...] um olhar mais centrado sobre os professores, sobre as suas vidas e os seus projetos, sobre as suas crenças e atitudes, sobre os seus valores e ideais, não ignorando as dimensões pessoais e profissionais do trabalho docente" (NÓVOA, 1995, p. 32).

De acordo com Queiroz (1988), trabalhar com história e relatos de vida é colocar a imperativa necessidade de ver os sujeitos participantes da pesquisa como seres sociais, seres de memória, de cultura e de história. Contudo, trabalhar com história de vida demanda um longo tempo e, certamente, várias sessões de entrevistas, porque nessa modalidade o entrevistado pode discorrer mais livremente sobre a sua vida, não tendo o cerceamento de sua narração pelo pesquisador. Por outro lado, nos relatos orais: 
A obediência do narrador é patente, o pesquisador tem as rédeas nas mãos. A entrevista pode se esgotar num só encontro, os depoimentos podem ser muito curtos, residindo aqui uma de suas grandes diferenças para com as histórias de vida (QUEIROZ, 1988, p.21).

Entretanto, neste estudo o intento é retomar, por meio dos relatos orais, os aspectos da vida pessoal e profissional de uma professora bem sucedida. Para isso, foi adotada, também, a perspectiva da autobiografia, na qual o entrevistado narra sua própria existência por meio da palavra oral. E por que oral? Porque, como alerta Queiroz (1988), o oral é a maior fonte humana de conservação e difusão do saber, uma das mais antigas técnicas para a difusão do conhecimento.

Assim, com a utilização da entrevista, busca-se registrar a experiência de um só indivíduo, outra importante marca do recurso metodológico de história de vida. Para Moita (1992), cada história, percurso ou processo de formação envolve trocas, experiências, interações sociais, aprendizagens, mas é único e singular.

Foi feito, então, o estudo de um caso, por se entender que o percurso da entrevistada é singular, não podendo servir como parâmetro para outros casos. Entretanto, como afirmam André e Lüdke (1986), o estudo de caso é assim chamado por se acreditar que seu resultado, embora se reporte a um contexto específico de pesquisa, pode ser útil para entender casos semelhantes.

Tendo como foco conhecer a história de vida de uma professora universitária considerada bem sucedida, por meio de seus relatos orais, procura-se responder às seguintes questões de pesquisa: como uma professora universitária, considerada bem sucedida, que atingiu o grau mais elevado da carreira acadêmica, recorda-se do seu início de profissão? Como ela vê as contribuições das diferentes instâncias de formação pelas quais passou?

A conversa/entrevista com a professora deu-se em uma única sessão, sendo usado como instrumento de pesquisa um roteiro semiestruturado. O relato oral da entrevistada foi guiado pelo interesse dos pesquisadores em conhecer o que ela tinha a dizer sobre o tema de pesquisa - a formação inicial de professores com ênfase na sua própria inserção profissional. Desse modo, alguns resultados da investigação são apresentados a seguir. 


\section{PROFESSORA PARTICIPANTE}

A entrevistada, com pseudônimo de Beatriz ${ }^{1}$, tinha 56 anos de idade, na época da entrevista. Fez Curso Normal $^{2}$ e Pedagogia e começou sua carreira no magistério em 1968, como professora eventual no ensino fundamental e médio, quando ainda cursava a graduação. Iniciou o mestrado em uma instituição do Estado de São Paulo, na área de Psicologia da Educação, em 1971, mas interrrompeu o curso antes de completar o primeiro ano, porque conseguiu uma bolsa de estudos num programa de ensino na Alemanha, onde ficou até 1974, estudando no setor de mídia e educação. Não havia terminado o mestrado em Psicologia da Educação, porém não quis retomá-lo por não se identificar mais com a proposta do curso. Como o curso feito na Alemanha não tinha equivalência aqui no Brasil, optou, quando da sua volta, por prestar outra seleção em uma instituição do Rio de Janeiro, na qual realizou também seu Doutorado, terminando-o em 1983.

Ingressou no magistério do Ensino Superior em 1975, em uma instituição privada, localizada na cidade do Rio de Janeiro, enquanto ainda cursava o mestrado. Em 1981, começou a dar aulas em uma universidade pública do interior de São Paulo, mediante aprovação em um concurso público para Professor Assistente. Permaneceu nessa instituição até o ano de 2004, quando saiu em virtude da aposentadoria. Fez concurso em 1991 para professora titular da disciplina Formação de Professores, do Programa de Pós-Graduação em Educação. E no ano de 1993 saiu para fazer pós-doutoramento na Santa Clara University, com bolsa da FAPESP.

Além de sua experiência docente, foi chefe de departamento por seis anos, tendo ajudado a criar o departamento ao qual estava vinculada quando houve a realização da entrevista; foi coordenadora do curso de pós-graduação em Educação, deu aulas no Projeto Alfa (um convênio com a Universidade de Salamanca - Espanha) e foi representante do Departamento de Educação na Associação de Docentes da Universidade.

À época da entrevista, Beatriz, após aposentar-se da instituição em que trabalhou por mais de vinte anos, encontrava-se trabalhando em outra universidade pública do Estado de São Paulo, em um novo

\footnotetext{
${ }^{1}$ Nome fictício atribuído a fim de garantir o sigilo sobre a identidade da professora participante. ${ }^{2}$ Normal é a modalidade do curso técnico, em nível de segundo grau, destinado à formação de professores para a Educação Infantil e as séries iniciais do Ensino Fundamental.
} 
momento de iniciação à docência.

\section{HISTÓRIA DE VIDA DE BEATRIZ}

Apresentam-se aqui os dados coletados durante a entrevista, sobre a trajetória de vida e de formação da entrevistada. Do relato feito por ela, procura-se absorver toda a riqueza de sua experiência pessoal e profissional, a fim de que possa servir ao objetivo de gerar novos conhecimentos, que auxiliem a formação de novos educadores. Entretanto, tendo em vista os limites deste trabalho, são focalizados somente os pontos referentes ao seu início de carreira e, também, ao seu atual momento, uma vez que está iniciando a carreira em outra instituição.

Todo o exercício profissional implica um período de iniciação no qual, geralmente, os mais experientes transmitem seu arcabouço teórico aos mais novos. No caso da docência, considera-se um iniciante como professor após cinco anos de exercício profissional. (GONÇALVES, 1995; HUBERMAN, 1995; TARDIF, 2O02; VEENMAN, 1988). Nesse período, ele sofre o que a literatura (por exemplo, Veenman) chama de choque da realidade.

A literatura sobre o início da profissão docente caracteriza esse momento como traumático, marcado por aprendizagens intensas. Huberman (1995) afirma que nesse período o professor se defronta com dois sentimentos: o da sobrevivência, que se caracteriza pela luta em não desistir da profissão, ao se deparar com todas as adversidades; e o da descoberta, que se caracteriza pelo fato de sentir-se um profissional, de descobrir-se enquanto profissional. Para o autor, é o segundo sentimento que permite a permanência do professor na profissão, superando o primeiro.

Tal sentimento não parece ter tomado conta de nossa entrevistada. Quando questionada sobre o choque da realidade, ela disse que não viveu esse momento, ressaltando que teve um início de carreira tranqüilo, e questionou a literatura que trata desse tema: "Eu diria que foi tranqüilo, não tive nada desses 'estremiliques', essas coisas todas. [...] não me lembro de ter tido dificuldades maiores. Não foi sofrido!"

O valor que atribui ao conhecimento de o que ensinar e a facilidade do relacionamento interpessoal podem ter ajudado a professora entrevistada no enfrentamento do momento inicial da docência. 
Percebe-se, então, a partir da declaração acima, que a entrada dos professores na carreira e o que eles vivenciam nesse início de vida profissional depende de seus conhecimentos prévios e de suas experiências de vida.

Ademais, contando com a experiência de alguém que já orientou trabalhos de pós-graduação e escreveu artigos sobre o início da docência, a professora teceu o comentário apresentado a seguir, quando foi questionada acerca do choque da realidade:

Então! Eu não sei se isso são choques, sabe por quê? O curso já te prepara pra enfrentar esse tipo de realidade. Pra mim o que é choque se resume a um aspecto muito específico no grau que eu tenho de domínio do conhecimento específico que vou trabalhar. (grifo dos autores).

Acerca da expressão cunhada por Veenman (1988), a entrevistada acrescenta: "Então, esse choque da realidade é genérico. Pra mim, ele tem que ser qualificado. E também serve como desculpa, pois se não está dando certo é porque eu não estou preparada para a realidade."

Em consonância com as idéias da professora Beatriz, é possível verificar que nos dias atuais, tendo em vista as políticas educacionais estabelecidas pelos órgãos governamentais, atribui-se aos cursos de formação inicial um papel maior do que eles podem cumprir. Eles não estão isentos de crítica e têm, portanto, necessidade urgente de serem alterados quanto às suas prioridades e organização. A respeito disso, a entrevistada coloca:

E os cursos de formação pelo menos deveriam trabalhar no sentido de mostrar a importância de o professor ter clareza disso. Eu não sei se o choque é de 'Ah! Nossa! Eu não sabia que era assim!' Eu acho que são por aí as coisas, não acho tão dramático."

Zeichner (apud MIZUKAMI et al., 2002), no que tange a esse assunto, elucida que não se pode esperar que os cursos de formação inicial funcionem como panacéia para toda a carreira de um professor, que dura em média 30 anos, pois o que eles podem fazer é, no máximo, preparar os alunos para começarem a ensinar. E, nesse aspecto, a indicação da professora é muito importante: tais cursos 
devem explicitar as características do período de iniciação e não apenas formar para atuar em contextos idealizados.

Desse modo, tendo em vista o depoimento da professora sobre o seu início de carreira e suas considerações acerca da necessidade de melhor explicitar o que é o choque do real, parece importante questionar: as fases propostas por Huberman (1995), no ciclo de vida profissional dos professores, são lineares e estanques? Estão presentes na iniciação profissional de todos os professores?

Considera a entrevistada que "[...] o problema do professor iniciante é justamente esse, essa barca de conhecimento que é limitada e não tem outro jeito de não ser limitada; é mesmo, porque é a partir do exercício do magistério que o professor vai começar a ampliar suas experiências e conhecimentos."

Quando questionada sobre o seu início na docência no ensino superior, que pelas características diferenciadas com relação aos demais níveis de ensino poderia ser considerada uma iniciação diferente, Beatriz também não menciona ter passado pelo referido choque. Marcelo García (1999), no que diz respeito a esse assunto, considera que cada vez que o professor muda de nível de ensino ou mesmo de instituição, pode sofrer o choque, o que não corresponde ao caso da entrevistada.

Acerca do ingresso na instituição em que trabalhou durante vinte e três anos, ela afirma que seu início foi tumultuado, porém não considera que houve um choque, e sim momentos conturbados na sua vida pessoal, pelo motivo de na época cursar doutorado em uma instituição localizada em outro estado. Coloca, ainda, as dificuldades oriundas da falta de estrutura do curso, pelo fato de ser novo, assim como da própria universidade, ao obrigá-la, por exemplo, a ministrar aulas na casa de uma aluna que se encontrava em licença gestante:

Não me relacionei muito com as pessoas no $1^{\circ}$ e no $2^{\circ}$ ano em que eu estava aqui, porque como estava passando por alguns problemas pessoais e tinha que terminar o doutorado, eu fiquei muito mais confinada. Nos espaços que eu tinha, eu ficava com a tese... Então, eu diria que socializei muito pouco.

Ao falar do início da carreira em uma outra instituição, depois de decorridos mais de trinta (30) anos de profissão, novamente a professora colocou em xeque o choque do real: "Quando eu entrei na 
Unesp, tive que reaprender tudo de novo. Choque da realidade eu não tive! Eu tive que entender contextos diferentes. Acho que isso é muito diferente do choque da realidade."

Tal fala parece sugerir que existe uma diferença entre aprendizagem e socialização em novos contextos e o choque do real, tal como citado na literatura. Assim, Beatriz dá a entender, também, que aposentadoria por tempo de serviço não é sinal de desinvestimento ou desânimo com a carreira profissional, pois mesmo recém-aposentada, está atuando em uma nova instituição pública de São Paulo, com aprovação em concurso, e aprendendo muitas coisas novas.

Em contrapartida, a professora Beatriz considera que as dificuldades que caracterizam esse início de carreira são superadas ao longo do exercício de aprender a ser professor e que os empecilhos não acontecem somente no começo da profissão, mas em qualquer uma das suas fases, como se pode constatar pelo relato transcrito a seguir:

[...] eu trabalhava na Pedagogia durante muito tempo com essa disciplina Didática 4 e achava que estava super segura, até que peguei uma turma que eu não conseguia Plano A, Plano B, Plano C, Plano $D$, nada. [...] Daí nada dava certo, até que um dia eu usei uma estratégia de desespero e deu certo. Mas, demorou uns dois meses para eu conseguir fazer alguma coisa com a turma. Isso tem uns 5 ou 6 anos; dá para ver que a gente não tem certeza das coisas. $E$ era uma disciplina que eu já ministrava fazia tempo.

A declaração acima é a clara tese de que o processo de aprendizagem profissional da docência, como defendido por Mizukami et al. (2002), não tem um fim estabelecido a priori. Independentemente do tempo que tenha de profissão, todos os dias o professor é submetido a aprendizagens intensas, o que torna sua profissão um verdadeiro e constante processo de aprender para ensinar e aprender a ensinar. Para Gonçalves (1992), esses momentos de crise são necessários e enriquecedores, pois são eles que preparam e motivam os momentos de progresso.

Por fim, quando questionada sobre quais aprendizagens lhe foram proporcionadas pelas várias disciplinas ministradas, bem como sobre o contato com os mais variados tipos de alunos, Beatriz declara: "Eu acho que está tudo muito relacionado. Não sei lhe dizer 
se eu contribuí, se elas contribuíram, ou se os alunos contribuíram. Acho que é um processo muito interativo. E é bom dar disciplinas diferentes, porque você aprende."

Nesse sentido, verifica-se que a profissão docente não se constitui de dimensões fragmentadas que podem perfeitamente ser separadas. O que se percebe é que, para dar configuração à sua identidade profissional, os vários lócus de formação e atuação do professor se imbricam constantemente. Como entende Moita (1992), não há uma unidimensionalidade na profissão docente, não há o sobrepujar de uma dimensão da vida do professor sobre a outra. Há papéis que, em determinados momentos da vida, têm um caráter dominante, mas não são exclusivos. Todos os contextos em que o professor se insere atuam como agentes de sua formação.

\section{CONSIDERAÇÕES FINAIS}

A singularidade do caso de Beatriz contribui para que se realizem discussões interessantes e produtivas acerca da formação e da trajetória profissional de docentes.

Por meio desta pesquisa, constata-se o quão é rico o recurso metodológico dos relatos orais para se buscar informações sobre histórias de vida de professores considerados bem sucedidos, como uma possível contribuição para a formação de outros docentes. Observase, também, que "[...] falar de si pode restaurar o sentimento de domínio de sua própria vida, da mesma forma que pode recuperar a integralidade de sua personalidade" (CATANI, 2000, p. 40). Pode, ainda, servir como rica fonte de conhecimento e exemplo para futuros professores.

Percebe-se que um professor não se forma apenas pelas vias acadêmicas, através de cursos de formação inicial e continuada. Forma-se pelas inúmeras relações interpessoais e profissionais estabelecidas, pelas experiências cotidianas, pelo ambiente familiar e pela convergência entre a teoria e a prática pedagógica.

Segundo a teoria de Huberman (1992), a vida profissional de um professor, comprovada, no caso, pelo relato oral de vida da entrevistada, é um processo contínuo e não apenas uma série de acontecimentos desconectados.

Destaca-se, nesse processo, o movimento ininterrupto de aprendizagem, em diferentes instâncias profissionais, mencionadas 
por Beatriz na entrevista. A professora não teve receio de enfrentar os desafios que lhe foram colocados pela profissão e isso certamente enriqueceu seu percurso pessoal e profissional.

Contudo, além da observação de alguns aspectos pertinentes na tese de Huberman (1995), outros podem ser questionados. Haveria, necessariamente, um choque da realidade no início da profissão? Se a resposta a essa pergunta for sim, o que isso significa?

Nesse sentido, os aspectos levantados pelo depoimento da professora Beatriz indicam a necessidade de melhor definir o que seria esse sentimento de choque e em quais circunstâncias e contextos ele ocorreria.

Além dos muitos dados propiciados por este estudo nas áreas em que a professora possui experiência, tanto como pesquisadora, como orientadora e como responsável por cargos administrativos, a sua história profissional foi construída com responsabilidade, competência, compromisso e rigor acadêmico. Esse é, sem dúvida, um exemplo ético a ser seguido por todos os professores.

\section{REFERÊNCIAS}

ANDRÉ, M.; LÜDKE, M. Pesquisa em educação: abordagens qualitativas. São Paulo: EPU, 1986.

CATANI, D. B. et al. História, memória e autobiografia na pesquisa educacional e na formação. In: . (Org.). Docência, memória e gênero: estudos sobre formação. São Paulo: Escrituras, 2000. p.13-46.

GONÇALVES, J. A. M. A carreira das professoras do ensino primário. In: NÓVOA, A. (Org.). Vidas de professores. Portugal: Porto, 1995. p.141-169.

GOODSON, I. F. Dar voz ao professor: as histórias de vida dos professores e o seu desenvolvimento profissional. In: NÓVOA, A. (Org.). Vidas de professores. Portugal: Porto, 1992. p.63-78.

HUBERMAN, M. O ciclo de vida profissional dos professores In: NÓVOA, A. (Org.). Vidas de professores. Portugal: Porto, 1995. p. 31-61.

MARCELO GARCÍA, C. Formação de professores - para uma mudança educativa. Portugal: Porto, 1999.

MIZUKAMI, M. G. N. et al. Escola e aprendizagem da docência: processos de investigação e formação. São Carlos: EDUFSCar, 2002. 
MOITA, M. C. Percursos de formação e de trans-formação. In: NÓVOA, A. (Org.). Vidas de professores. Portugal: Porto, 1992. p.111-140.

NÓVOA, A. Diz-me como ensinas, dir-te-ei quem és e vice-versa. In: FAZENDA, I. C. A. (Org.). A pesquisa em educação e as transformações do conhecimento. Campinas: Papirus, 1995. p. 29-41.

QUEIRÓZ, M. I. P. Relatos orais: do "indizível" ao "dizível". In: SIMSON, O. R. M. Experimentos com histórias de vida: Itália - Brasil. São Paulo: Vértice, 1988, p. 15-42.

TARDIF, M. Saberes docentes e formação profissional. 2. ed. Petrópolis: Vozes, 2002.

VEENMAN, S. El Proceso de llegar a ser profesor: una análisis de la formación inicial. In: VILLA, A. (Coord.). Perspectivas y problemas de la funcción docente. Madrid: Narcea, 1988, p. 39-68.

Encaminhado em: 06/02/07

Aceito em: 22/05/07 